\title{
Boron and cesium leachability from cementitious waste forms containing B-10 enriched boric acid
}

MOJTABA ROSTAMIPARSA ${ }^{1}$, EMANUEL NKOTYA ${ }^{1}$, ISTVÁN TOLNAI ${ }^{2}$, MARGIT FÁBIÁN $^{2}$, GYÖRGY FALUS $^{3}$, CSABA SZABÓ $^{4}$, ZSUZSANNA SZABÓ-KRAUSZ ${ }^{4}$ AND PÉTER VÖLGYESI ${ }^{5}$

${ }^{1}$ Eötvös Loránd University

${ }^{2}$ Hungarian Centre for Energy Research

${ }^{3}$ Mining and Geological Survey of Hungary

${ }^{4}$ Eötvös University

${ }^{5}$ Centre for Energy Research

Presenting Author: mojtabarostami466@gmail.com

Boric acid enriched in B-10 (enriched boric acid, EBA) is a new and more effective neutron absorber in nuclear technology instead of natural boric acid (NBA). The volume of radioactive wastes containing EBA is increasing continually whereas there is no data about safe conditioning and the durability of the final waste forms containing this new neutron absorber.

In this study, boron leachability from cementitious matrices was selected as an approved index for the comparison of simulated final waste forms durability[1]. These solids were made of Portland cement, water, $\mathrm{NaOH}$ and contain either NBA or EBA with different concentrations. Some samples also incorporate cesium to test its simultaneous leachability. Changes in chemical and mineral compositions of the solid samples were assessed by XRD and SEM techniques. The total released boron, its isotopic ratio, and cesium concentrations in extracted leachates were measured by ICP-OES and ICP-MS analyses[2] [3].

The results show that the mineralogy of the cementitious matrices changes with concentrations and enrichments of boric acid. Also, the ${ }^{10} \mathrm{~B} /{ }^{11} \mathrm{~B}$ ratio in the extracted solution decreases during the 11 days long test. This indicates an isotopic fractionation during the leaching tests. Furthermore, the cementitious solid samples containing EBA indicated a lower boron leachability up to $30 \%$ in comparison to the solid samples made with NBA. Nevertheless, adding cesium may change both mineralogy and boron leachability. It is important to confirm the boron and cesium leachability relation where EBA is contained in cementitious matrices.

[1] “ASTM C1308-08(2017), Standard Test Method for Accelerated Leach Test for Diffusive Releases from Solidified Waste and a Computer Program to Model Diffusive, Fractional Leaching from Cylindrical Waste Forms, ASTM International, West Conshohocken, PA, 2017,.”.

[2] H. Marschall and G. Foster, Advances in Isotope Geochemistry-Boron isotopes. Switzerland: Springer, 2018.

[3] S. Böhlke, C. Schuster, and A. Hurtado, "About the volatility of boron in aqueous solutions of borates with vapour in relevance to BWR-reactors," in International Conference on the Physics of Reactors " Nuclear power: A sustainable resource," 2008, vol. 4, no. September 2008, pp. 3089-3096. 